\title{
Design of a Control System for Magnetic Plate-type Precision Seeding Production Line Based on PLC and MCU
}

\author{
Yan Xiaoyue, Hu Jianping ${ }^{*}$, Ma Jun and Wang Xun
}

Laboratory of Modern Agricultural Equipment and Technology, Ministry of Education\&Jiangsu Province, Jiangsu University, Zhenjiang, 212013, China

\begin{abstract}
Based on the magnetic seed-metering principle, a new magnetic plate-type precision seeder and seeding production line were developed to meet the requirements of precision seeding. The control system was designed based on Programmable Logic Controller (PLC) and Mico Controller Unit (MCU). Automatic programming techniques, sensor technology, acceleration and deceleration control of step motor were integrated into the system. The PLC control system controls the workflow of the production line to realize accurate positioning of the tray and its coordination. The MCU control system controls the flip of the sowing board, as well as the up-and-down movement of the seed case for whole tray seed-filling and sowing. Seeding tests for the magnetic powder coated rape seeds showed that the rates of single-seeding, over-seeding and miss-seeding were $90.2778 \%, 4.6875 \%$ and $5.0347 \%$ respectively. The seeding speed was up to $14 \mathrm{~s}$ per tray. This result meets the requirements of precision seeding.
\end{abstract}

Keywords: Magnetic Plate-type Seeder, Seeding Production Line, Precision Seeding, PLC, MCU, Control System.

\section{INTRODUCTION}

Precision seeding requires accurate number of seeds, spacing and sowing depth. It has advantages of saving seeds, reducing thinning time and improving crop yields. This is the main focus of modern agriculture, which replaces traditional individual seeding processes [1]. Most factory breeding production lines are developed on the basis of the precision seeding technology. Their workflow includes subsoil covering, holes punching, sowing, watering and topsoil covering etc. There have been reports in recent years about precision seeding production lines, varying from manual operation to mechanized, continuous and automatic production lines [2, $3]$. From the magnetic seed-metering principle, this paper developed a novel magnetic plate-type precision seeder and seeding production line aimed at ensuring the requirements of precision and high uniformity. The seeder comprises LJD$51-\mathrm{XB}+\mathrm{MCU}$ with one photoelectric sensor and four proximity sensors to control the acceleration and deceleration of two step motors. This MCU system is meant to allow the movement of the seed case and the flip of the sowing board. The production line comprises DVP-40ES PLC with five photoelectric sensors and one proximity sensor to control the seven single-phase AC motors. This PLC system is designed to achieve the tray conveying, subsoil covering, holes punching, watering and topsoil covering. The coordination of two systems enhanced the accurate positioning of the tray and precision seeding operations. The objective of this study was to design a control system for magnetic plate-type precision seeding production line.

*Address correspondence to this author at the Laboratory of Modern Agricultural Equipment and Technology, Ministry of Education\&Jiangsu Province, Jiangsu University, Zhenjiang, 212013, China; Tel: 13852984643; Fax: 0511-88797338; E-mails: hujp@ujs.edu.cn, xiaoyuelancao@163.com

\section{THE STRUCTURE AND WORKING PRINCIPLE OF THE MAGNETIC PLATE-TYPE PRECISION SEEDER AND SEEDING PRODUCTION LINE}

\subsection{Precision Seeding Production Line}

The permanent magnetic plug plate-type precision seeding production line included six workflows: tray conveying, subsoil covering, holes punching, sowing, watering and topsoil covering. The structure diagram of the production line is shown in Fig. (1).

The work-flow is as follows: 1) trays are conveyed; 2) subsoil-covering motor drives the covering wheel which tends to fill the tray with substrates, after which the brush removes excess substrates from the surface of the tray; 3 ) plate-type holes-punching mechanism punches holes for the whole tray; 4) the sowing board which has completed seedfilling flips to drop seeds into the corresponding holes in the tray cells; 5) water and then cover seeds with substrates, after which the other brush removes excess substrates from the surface of the tray again, while the sowing board flips back to the original position and completes seed-filling to prepare for the next seeding cycle [4].

\subsection{Magnetic Plate-type Precision Seeder}

The seeder is a core component of the seeding production line and uses permanent magnetic plugs as seeding elements. It consists of a pinion, rack, seed case and sowing board, permanent magnetic plugs, mandrils, two motors (one is to drive the movement of the seed case, while the other drives the sowing board flip). The schematic working structure is shown in Fig. (2).

The work-flow of the seeder is as follows: 1) The sowing step motor drives the sowing board flip to the seed-filling zero position (the seed-filling angle is greater than 90 de- 


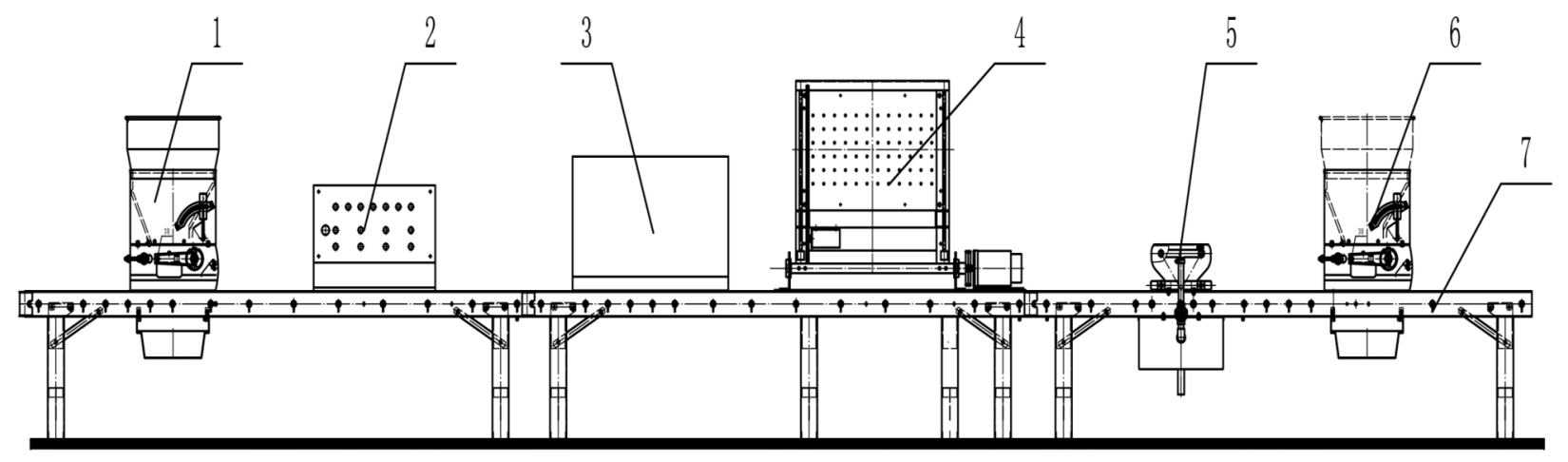

1. Subsoil coving part 2. Control cabinet 3. Holes punching part 4. Sowing part 5. Watering part 6 . Topsoil covering part 7. Tray conveying frame

Fig. (1). Structure diagram of magnetic plate-type precision seeding production line.

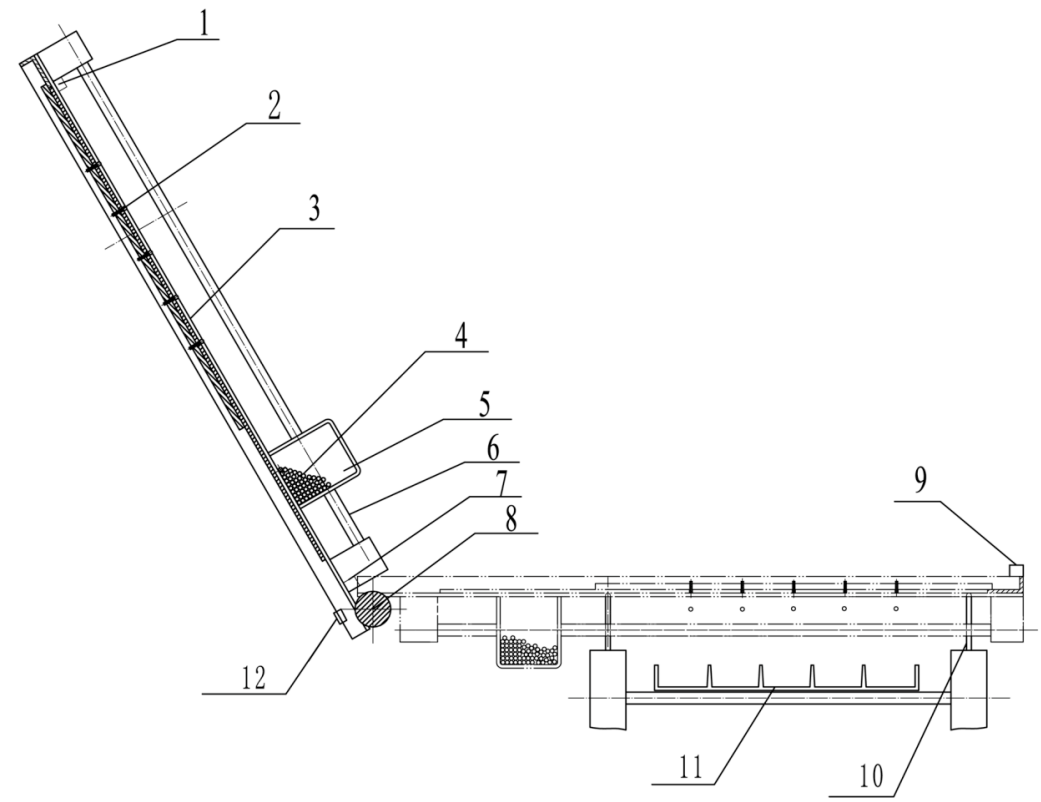

1. Proximity sensor 2 2. Permanent magnetic plug 3. Sowing board 4. Magnetic powder coated seeds 5. Seed case 6. Linear guide 7. Proximity sensor 3 8. Shaft 9. Proximity sensor 4 10. Mandril 11. Tray 12. Proximity sensor 1

Fig. (2). Schematic structure diagram of magnetic plate-type precision seeder.

grees and less than 180 degrees). 2) In the meantime, the seed case, along the linear guide, moves from the bottom of the sowing board to the top and then returns. 3) In the process of the seed case returning, the permanent magnetic plugs absorb the magnetic powder coated seeds to complete seedfilling. 4) The sowing board flips down to the sowing zero position (the horizonal position) and the mandrils push the mounting plate of the magnetic plugs up to separate seeds and permanent magnetic plugs and decrease the magnetic attraction force that seeds received. 5) The seeds then drop into their corresponding holes in the tray cells when the magnetic attraction force is less than gravity. 6) The sowing board flips up and the mounting plate of the magnetic plugs returns to its original position under the action of the springs to prepare for the next cycle $[5,6]$.

The magnetic plate-type seeder has the following advantages: 1) Permanent magnetic plugs are mounted on the sow- ing board in accordance with the tray size to ensure that the seeder can achieve precision seeding for the whole tray in one cycle. 2) It is easy to install and adjust due to its simplicity in structure. 3) The permanent magnetic plug can provide enough magnetic attractive force to ensure simple and reliable seed-filling and seed-clearing. 4) The magnetic force value can be adjusted by changing the projecting length of the plug in order to improve the adaptability for different seeds and the effectiveness of the seeder.

\section{DESIGN OF THE PRECISION SEEDING PRO- DUCTION LINE CONTROL SYSTEM}

\subsection{Hardware Selection}

For the seeding production line, the single-phase AC motors were used as the power source. 90YYJ (T) 120-30 motors were adopted. Its controller was ES / EX series Delta DVP-40ES PLC. 
Table 1. Distributions of $I / O$ in the PLC control system

\begin{tabular}{|c|c|c|}
\hline Class & Points & Description \\
\hline \multirow{17}{*}{$\begin{array}{c}\text { Input relay } \\
\mathrm{X}\end{array}$} & $\mathrm{X} 0$ & Emergency Stop \\
\hline & $\mathrm{X} 1$ & Start of the production line \\
\hline & $\mathrm{X} 2$ & Stop of the production line \\
\hline & $\mathrm{X} 3$ & Manual/automatic switching \\
\hline & $\mathrm{X} 4$ & $\begin{array}{c}\text { Start of the motor for tray conveying during } \\
\text { subsoil covering }\end{array}$ \\
\hline & $\mathrm{X} 5$ & Start of the motor for subsoil covering \\
\hline & $\mathrm{X} 6$ & $\begin{array}{c}\text { Start of the motor for tray conveying during } \\
\text { holes punching }\end{array}$ \\
\hline & $\mathrm{X} 7$ & Start of the motor for holes punching \\
\hline & $\mathrm{X} 10$ & $\begin{array}{c}\text { Start of the motor for tray conveying during } \\
\text { sowing }\end{array}$ \\
\hline & $\mathrm{X} 11$ & $\begin{array}{c}\text { Start of the motor for tray conveying during } \\
\text { watering and topsoil covering }\end{array}$ \\
\hline & $\mathrm{X} 12$ & Start of the motor for topsoil covering \\
\hline & $\mathrm{X} 13$ & $\begin{array}{l}\text { Tray is conveyed to the position for subsoil } \\
\text { covering }\end{array}$ \\
\hline & $\mathrm{X} 14$ & $\begin{array}{l}\text { Tray is conveyed to the position for holes } \\
\text { punching }\end{array}$ \\
\hline & $\mathrm{X} 15$ & The completion of holes punching \\
\hline & $\mathrm{X} 16$ & Tray is conveyed to the position for sowing \\
\hline & $\mathrm{X} 17$ & Tray is conveyed to the position for watering \\
\hline & $\mathrm{X} 20$ & $\begin{array}{l}\text { Tray is conveyed to the position for topsoil } \\
\text { covering }\end{array}$ \\
\hline \multirow{8}{*}{$\begin{array}{c}\text { Output } \\
\text { relay } \\
\mathrm{Y}\end{array}$} & Y0 & Tray conveying during subsoil covering \\
\hline & Y1 & Subsoil covering \\
\hline & Y2 & Tray conveying during holes punching \\
\hline & Y3 & Holes punching \\
\hline & Y4 & Tray conveying during sowing \\
\hline & Y5 & $\begin{array}{c}\text { Tray conveying during watering and topsoil } \\
\text { covering }\end{array}$ \\
\hline & Y6 & Watering \\
\hline & Y7 & Topsoil covering \\
\hline
\end{tabular}

For the sowing part, the flip of sowing board and the upand-down movement of seed case both adopted step motors to drive. The sowing board used 110BF-003 (new) type step motor driven by the BQH-300Y-type step motor driver as its power source. The seed case used 85STH118 type step motor driven by WZM-2H057M two-phase hybrid step motor subdivision driver as its power source. Also, LJD-51-XB + MCU was adopted to control the acceleration and deceleration of two step motors.

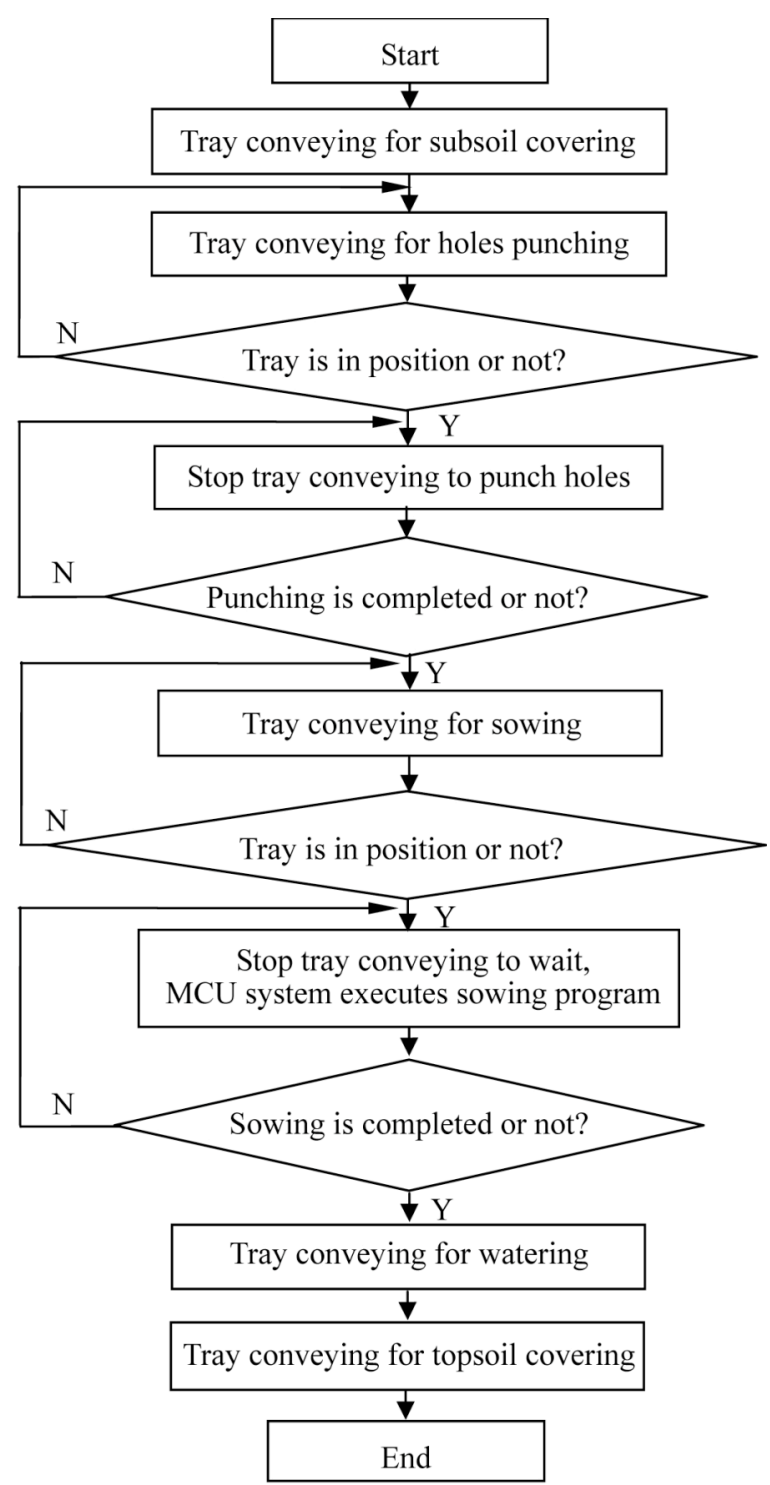

Fig. (3). Workflow chart of the PLC control system for one cycle.

To ensure accurate positioning of the tray, sowing board and seed case, SICK GL6-N1111 type photoelectric sensors and SND05-N-type capacitive proximity sensors were used for real-time detection of their locations and status $[3,7,8]$.

\subsection{Design of PLC Control System for Seeding Produc- tion Line}

The seeding production line control system consists of a DVP-40ES PLC, seven single-phase AC motors, a proximity sensor and five photoelectric sensors. It has 17 input signals and 8 output signals, the input/output distributionis shown in Table 1.

The seeding production line has both manual and automatic operating mode. The manual mode is for debugging and calibration of the initial stage; the automatic mode is for continuous production running [9].

As illustrated in Fig. (3), the workflow of the PLC control system for one cycle is as follows: Tray conveying starts after power-on reset, the subsoil-covering wheel turns to cover subsoil when the photoelectric sensor for subsoil- 


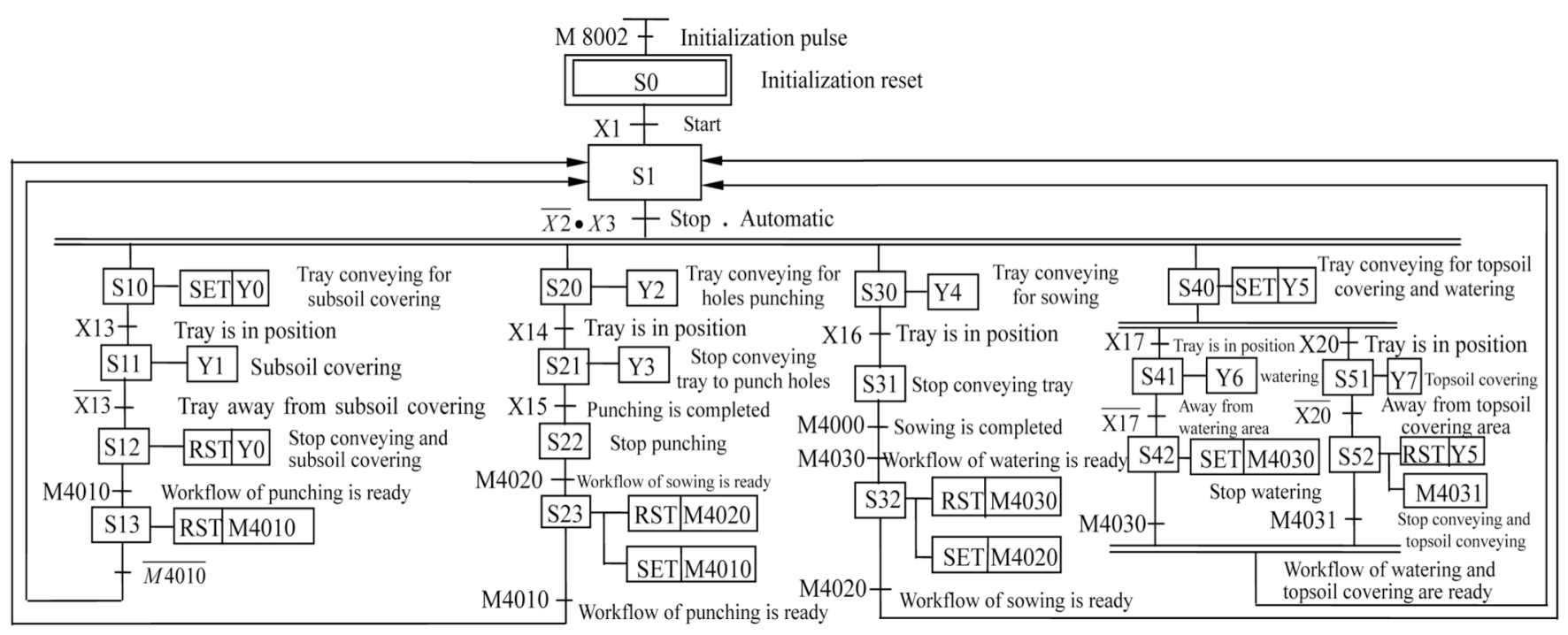

Fig. (4). Program state transition diagram of the PLC control system.

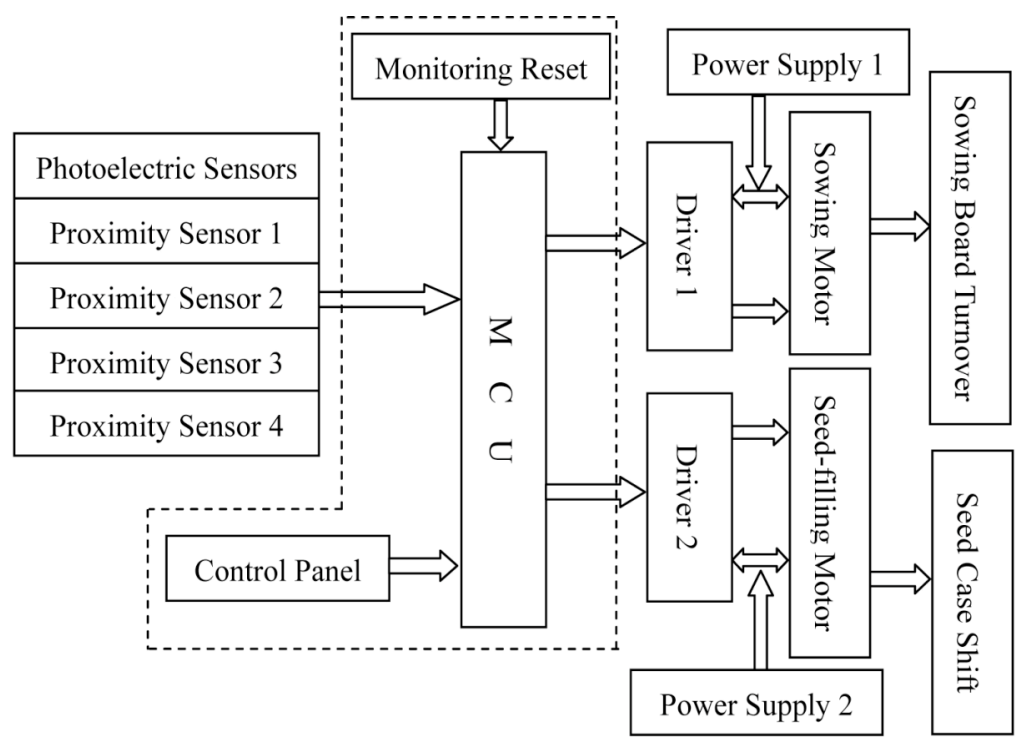

Fig. (5). Schematic diagram of the MCU control system.

covering detection (X13) senses the tray in place. Tray conveying then stops to punch holes for the whole tray when the photoelectric sensor for holes-punching detection (X14) senses the tray in place. Tray conveying continues after the completion of holes punching (X15). It stops and waits for a while for the photoelectric sensor (X16) to sense the tray in place for sowing. The tray conveys after the MCU control system completes sowing process. Watering then starts at the watering detection point (X17). The topsoil-covering wheel turns to cover topsoil at the photoelectric sensor (X20) detection position. The cycle then comes to an end and prepares for another cycle to begin.

The program state transition diagram of the PLC control system under the automatic operating mode is shown in Fig. (4).

\subsection{Design of MCU Control System for Magnetic Plate- type Precision Seeder}

The automatic control of the seeder comprises LJD-51$\mathrm{XB}+\mathrm{MCU}$ with its corresponding expansion of external circuit. Its control system consists of sensor signal acquisition module, CPU control module, optical isolation module, human-machine interface (control panel) and system monitoring reset module [10]. Its schematic diagram is shown in Fig. (5).

As illustrated in Fig. (6), the workflow of the MCU control system is as follows: the sowing board, driven by sowing step motor, flips up after switching on the power. When it flips to the seed-filling zero position (upon detection by proximity sensor 1), the board stops flipping and the seed case, driven by seed-filling step motor, moves up to the top of the sowing board (upon detection by proximity sensor 2), after which it moves down to the bottom (upon detection by proximity sensor 3) to complete seed-filling; the seeder then stops for a while to get a signal from the PLC control system (the tray is in place for sowing) . After the signal is received, the sowing board flips down to the horizonal position (the sowing zero position sensed by proximity sensor 4) for 0.3 seconds to ensure that seeds drop by gravity into the corresponding holes; after this, the sowing board flips up to the 


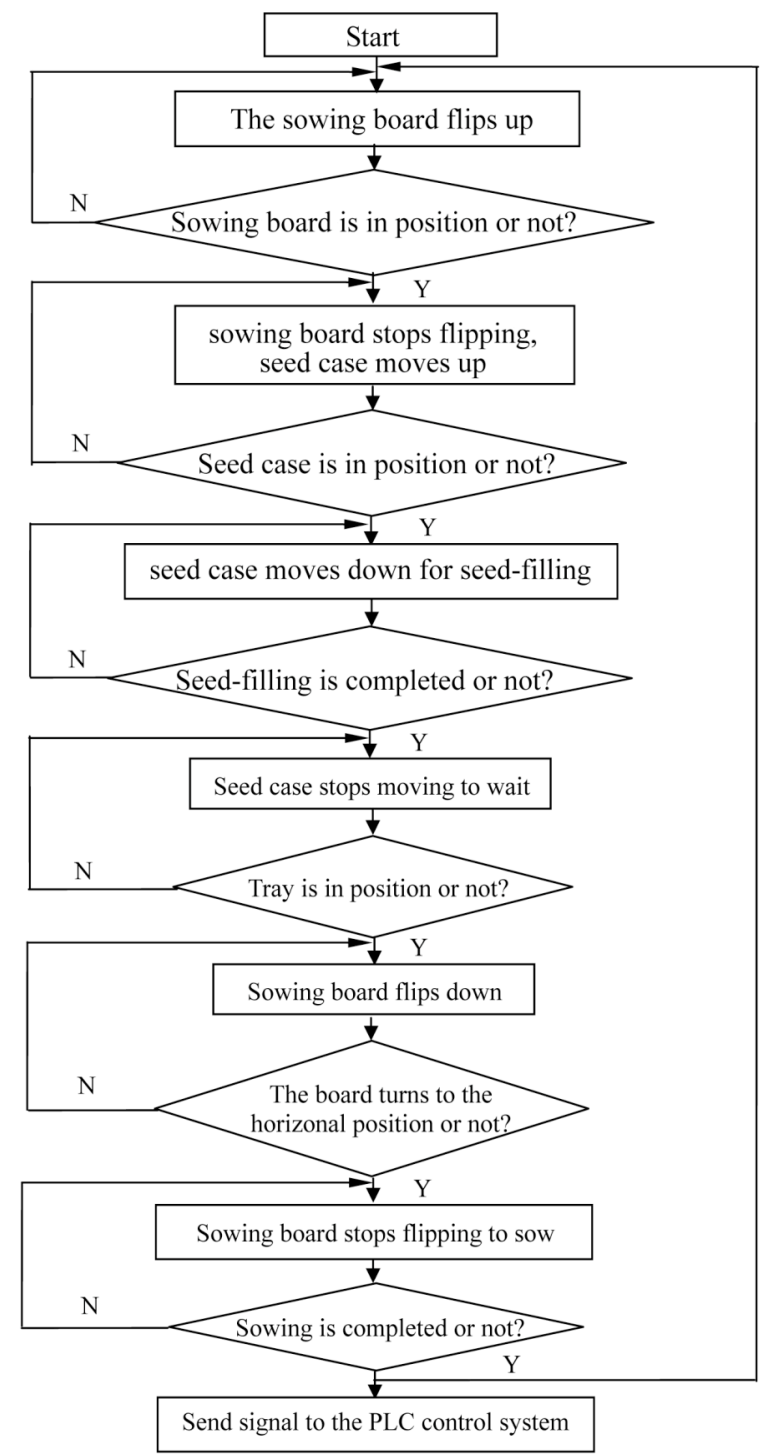

Fig. (6). Workflow chart for the MCU control system.

seed-filling zero position to complete the seed-filling and prepare for the next cycle.

\subsection{Design of Control System Reliability}

In order to overcome poor working environment of the seeding production line, the control system reliability design is needed to improve its anti-interference ability and ensure the stable and smooth running of this system [3].

PLC control systems often need independent power supply and good grounding in case there is external high voltage. High and low voltage routes are separated by $15 \mathrm{~cm}$ or more spacing to avoid interference with each other. Also, interlock functions are set for the safe and reliable control of relevant work units $[11,12]$. Specific measures were put in place in the program state transition diagram of the PLC control system (Fig. 4).

For MCU control system, the I/O is entirely made of photoelectric isolation in order to avoid the mutual influence of the system and other scene clutter signals. Power terminals decouple capacitors to absorb the pulse interference. Capaci- tors and relays are in parallel connection to absorb the back EMF that is generated when the circuit is instantaneously switched on and off. This helps avoid the damage to the seeding equipment and MCU [13, 14]. Specific measures were put in place in the MCU control system circuit diagram (Fig. 7).

\section{TESTS AND ANALYSIS}

The performance tests for the seeding production line control system, used 72 holes $(6 \times 12)$ per tray and the magnetic power coated rape seeds (with $10 \%$ magnetic power content) as test object. It was made up of two parts: 1) The single factor tests for the seeder to find out the influence of three seeding parameters (the seed-filling angle, the seed case moving speed and the sowing board flip angular velocity) on the seeding performance (the rate of single-seeding, over-seeding and miss-seeding). This helps determine the optimal seeding parameters of the seeder $[15,16]$. 2) The automatic seeding tests for the seeding production line to obtain the seeding performance indicators. This is aimed at ensuring the stability and coordination of the production line control system $[4,17]$.

\subsection{Tests for the Determination of Optimal Seeding Pa- rameters}

With different seed-filling angles $\left(110^{\circ}, 120^{\circ}, 130^{\circ}\right)$, varying the maximum input pulse frequency of the seedfilling step motor $(2000 \mathrm{HZ}, 2500 \mathrm{HZ}, 3000 \mathrm{HZ}, 3500 \mathrm{HZ}$, $4000 \mathrm{HZ}, 4500 \mathrm{HZ}$ ), tested for the seeder to find out the number of times over-seeding and miss-seeding occurred. Fig. (8) shows the variation curves of seeding performance indicators with the seed-filling steeper motor maximum input pulse frequency based on the seed-filling angle.

From the Fig. (8), it could be seen that: (1) Under the same motor frequency, the sum of miss-seeding and over-seeding in the case of $110^{\circ}$ is smaller than that in the case of $120^{\circ}$ and $130^{\circ}$. Therefore, the optimal seed-filling angle is $110^{\circ}$. (2) Under the same seed-filling angle, the sum of missseeding and over-seeding in the case of $4000 \mathrm{HZ}$ is also less than that in other frequency cases. Therefore, the optimal seed-filling step motor frequency is $4000 \mathrm{HZ}$.

With $110^{\circ}$ seed-filling angle and $4000 \mathrm{HZ}$ seed-filling motor frequency, tested under the different maximum input pulse frequency of the sowing step motor $(4000 \mathrm{HZ}, 4500 \mathrm{HZ}$, $5000 \mathrm{HZ}, 5500 \mathrm{HZ}, 6000 \mathrm{HZ}$ ) , the results of over-seeding and miss-seeding are showed in Fig. (9).

From the Fig. (9), it could be seen that: (1) The sum of miss-seeding and over-seeding in the case of $4500 \mathrm{HZ}$ is smallest. Therefore, the optimal sowing step motor frequency is $4500 \mathrm{HZ}$. (2) At $110^{\circ}$ seed-filling angle, $4000 \mathrm{HZ}$ seed-filling motor frequency and $4500 \mathrm{HZ}$ sowing motor frequency, the corresponding rates of single-seeding, overseeding and miss-seeding are $90.2778 \%, 4.6875 \%$ and $5.0347 \%$ respectively.

\subsection{Coordination Control Tests for the Seeding Produc- tion Line}

From the tests described above, the optimal seed-filling angle was found to be $110^{\circ}$, the optimal seed case moving 


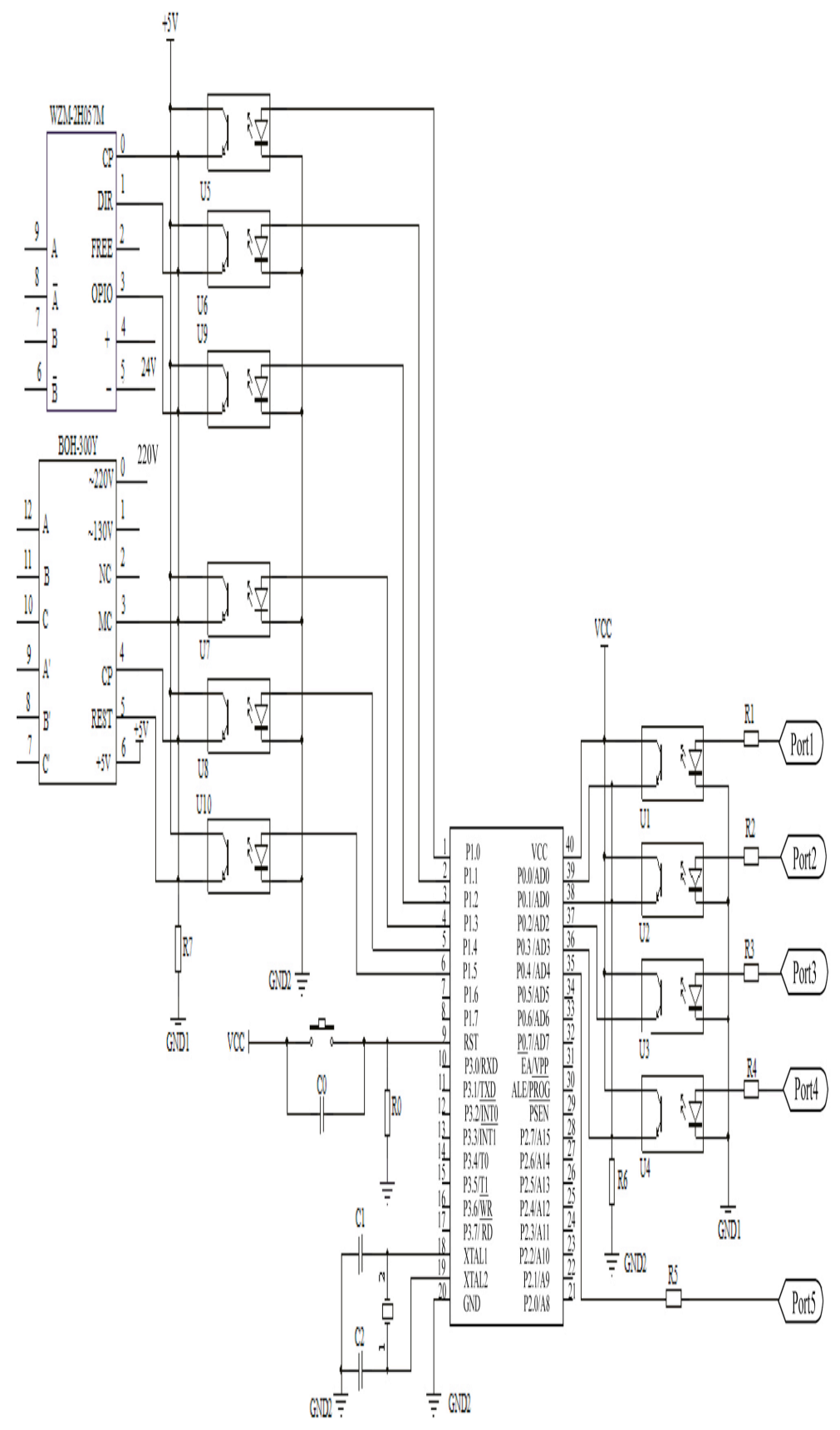

Fig. (7). MCU control system circuit diagram.

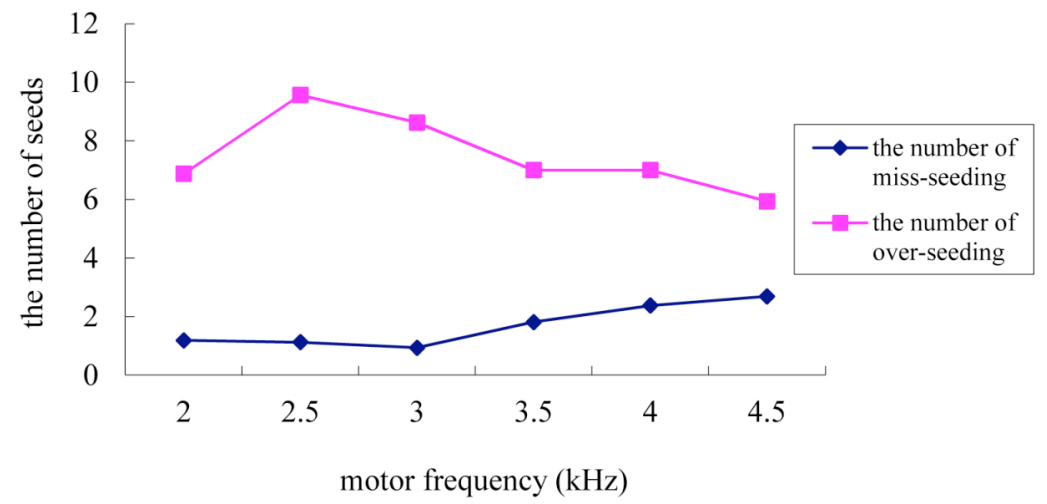

(a) the seed-filling angle $=110^{\circ}$ 


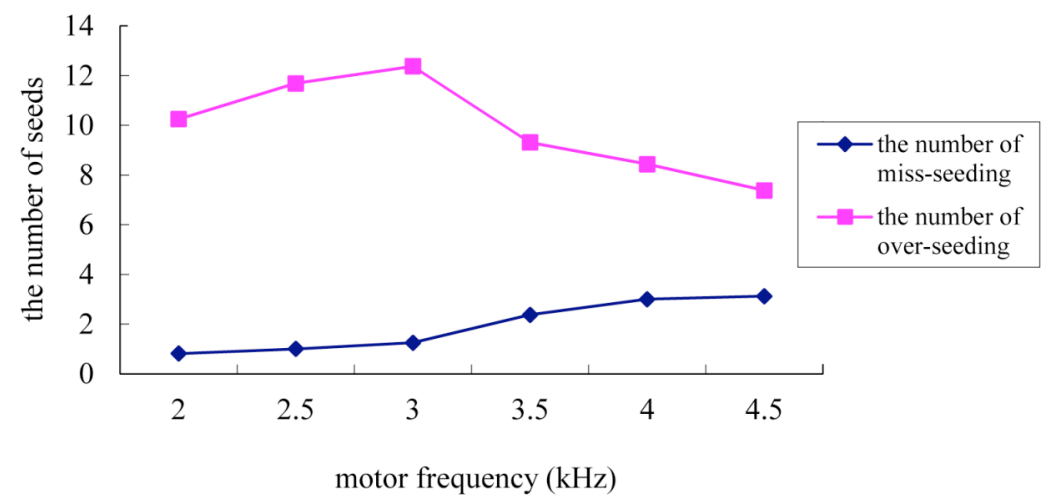

(b) the seed-filling angle $=120^{\circ}$

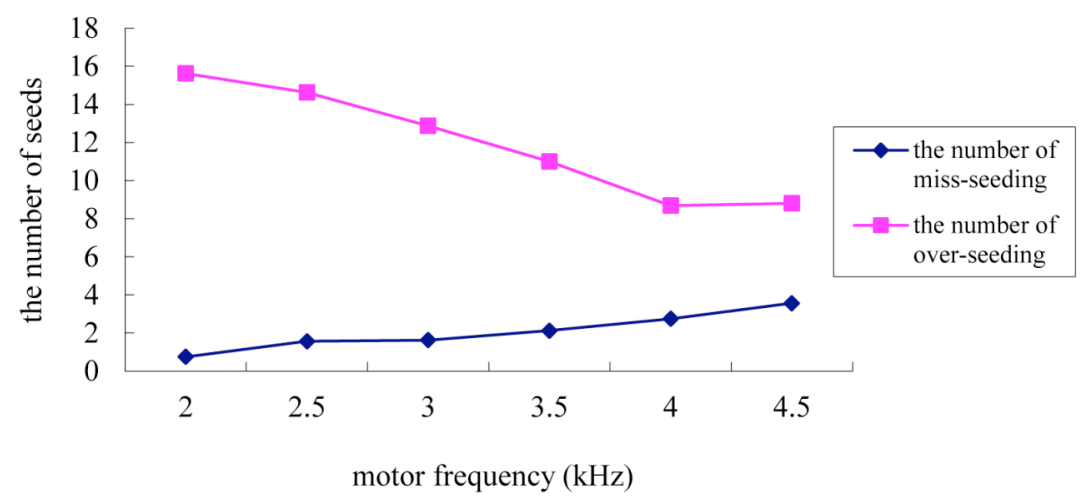

(c) the seed-filling angle $=130^{\circ}$

Fig. (8). The variation curves of seeding performance indicators with the seed-filling steeper motor maximum input pulse frequency.

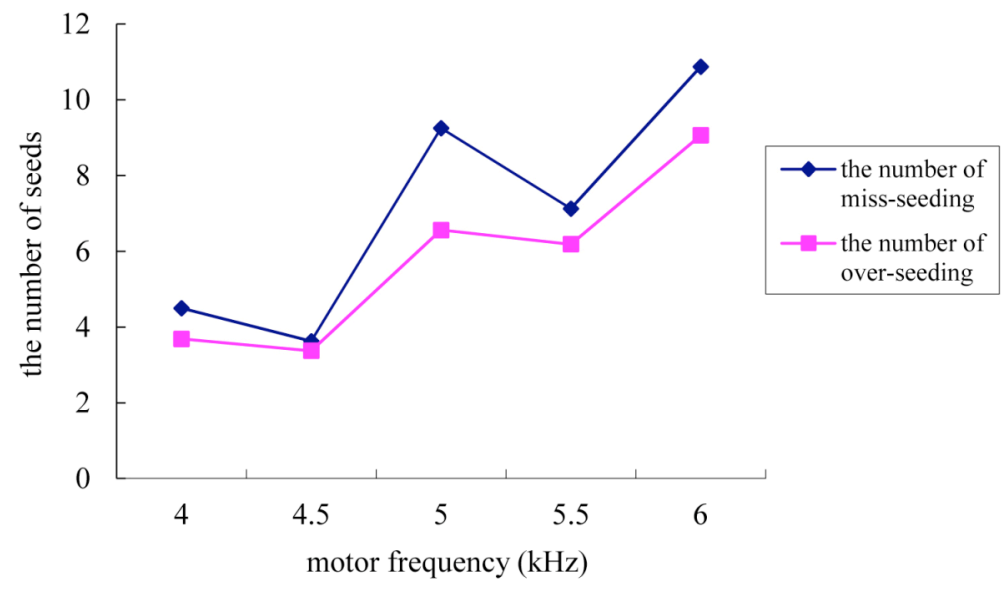

Fig. (9). The variation curves of seeding performance indicators with the sowing steeper motor maximum input pulse frequency.

speed being $0.08 \mathrm{~m} / \mathrm{s}$ (4000HZ seed-filling motor frequency) and the optimal sowing board flip angular velocity being $0.52 \mathrm{rad} / \mathrm{s}$ (4500HZ sowing steeper motor frequency). Under these conditions, automatic seeding tests for the production line were conducted to verify the efficiency of the system. The seeding speed realized in this study was 257/hour (an average of $14 \mathrm{~s}$ per tray), which meets the requirements of precision seeding.

\section{CONCLUSIONS}

1) Based on the magnetic seed-metering principle, a new magnetic plate-type precision seeder and seeding production line were developed for whole tray seed-filling and sowing.
2) The control system for the seeder and seeding production line was designed according to their working principles and precision seeding requirements. The seeder adopted LJD-51-XB + MCU system to achieve seed-filling and sowing control. The seeding production line also adopted DVP40ES-PLC system to enhance and control the entire workflow. The coordination between the two systems helped to achieve the accurate positioning of the trays and highquality seeding operations. The operations carried out tray conveying, subsoil covering, holes punching, sowing, watering and topsoil covering.

3) From the results, the optimal seed-filling angle was $110^{\circ}$, with an the optimal seed case moving speed of $0.08 \mathrm{~m} / \mathrm{s}$ 
and the optimal sowing board flip angular velocity of 0.52 $\mathrm{rad} / \mathrm{s}$. Under these conditions, seeding tests for the magnetic power coated rape seeds showed that the rate of singleseeding, over-seeding and miss-seeding were $90.2778 \%$, $4.6875 \%$ and $5.0347 \%$ respectively. The seeding speed was up to 257 /hour (an average of $14 \mathrm{~s}$ per tray). This meets the requirements of precision seeding.

\section{CONFLICTS OF INTEREST}

The authors confirm that this article content has no conflicts of interest.

\section{ACKNOWLEDGMENTS}

This work was financially supported by the natural science research important project of Jiangsu province universities (11KJA210001), Jiangsu Province Qing Lan Project (Su teacher (2010) no.27), the Priority Academic Program Development of Jiangsu Higher Education Institutions ( $\mathrm{Su}$ financial teacher (2011) no.8) and the Technology Support Program of Jiangsu province (Agricultural part, BE2011348).

\section{REFERENCES}

[1] J. K. Li, Q. L. Zhang, and B. Han, "Developing Tendency of Modern Facility Agriculture”, Manage. Agric. Sci. Technol., vol. 23, no. 3, pp. 36-37, March. 2004.

[2] J. P. Xu, Y. F. Xie, and T. Xu, "The Present Technic Status and Developing Tendency of the Domestic and Abroad Drill", J. Agric. Mech. Res., no. 2, pp. 232-237, February 2010.

[3] S. S. Yu, W. Y. Zhang, C. Y. Wu, and M. Zhang, "Design of PLC control system of precise seeding assembly line for rice seedling nursing", Trans. CSAE, vol. 25, no. 11, pp. 202-207, November 2009.
[4] J. P. Hu, Z. Q. Liu and Z. Y. Zuo, " Design of magnetic plug seedling sower automatic control system", Mach. Des. Мапи., no. 1, pp. 177-178, January 2008.

[5] Jiangsu University, "Permanent Magnetic Plug Plate-type Precision Seeder", Chinese Patent 201110421840.1, June 27, 2012.

[6] Jiangsu University, "A Electronic Magnetic Plug Plate-type Precision Seeder", Chinese Patent, 201110421839.9, June 27, 2012.

[7] P. X. He, M. J. Yang and Z. H. Chen, "Study on photoelectric controlled precision seeder", Trans. CSAM, vol. 34, no. 1, pp. 4749, January 2003.

[8] M. D. Liu, X. J. Lu and X. Qi, "Design of automatic seedling production line based on AT89S52", Trans. CSAE, vol. 28, no. 2, pp. 229-232, February 2012.

[9] L. Gao, N. K. Wang and Y. Gao, "Fuzzy control on air-suction seeding system in the seedling production line", J. Beijing For. Uni., vol. 29, no. 4, pp. 75-79, April 2007.

[10] W. Wang, "Investigation on the Enhancement of Reliability for the Anti-interference and Grounding System of PLC Systems", Pro. Auto. Inst., vol. 31, no. 8, pp. 55-57, August 2010

[11] S. Chen, "Design of PLC Control Program Reliability", Indust. Control. Comput., vol. 25, no. 9, pp. 120-122, September 2012.

[12] X. R. Ren, "Reliability Design of Single Chip Microcomputer System", Comput. Auto. Meas. Control, vol. 11, no. 8, pp. 621-626, August 2003.

[13] C. Lu, "The Design of Anti-interference and Reliability in MCU System", Instrum. Technol., no. 2, pp. 43-48, February, 2010.

[14] J. P. Hu, S. N. Zheng and W. D. Liu, "Design and experiment of precision magnetic cylinder seeder", Trans. CSAM, vol. 40, no. 3, pp. 60-63, March 2009.

[15] M. J. Xin, Y. Q. Song, W. T. Ren, X. H. Bai, and Y. Q. Hu, "Control system for constant pressure metering of fluid sowing machine". In: 2011 International Conference on Electronic and Mechanical Engineering and Information Technology, 2011, pp. 35053508 .

[16] J. p. Hu, Q. R. Wang and X. P. Shao, "Simulation on Magnetic Precision Seed-metering Device", Trans. CSAM, vol. 41, no. 12, pp. 35-38, December 2010.

[17] Y. W. Zhang, "Research and design for making a new type of mechanized and multiple functions of precision seed-drilled appliance", Trans. CSAM, vol. 36, no. 3, pp. 50-58, March 2005.

Received: July 02, 2013

Revised: July 07, 2013

Accepted: July 14, 2013

(C) Xiaoyue et al.; Licensee Bentham Open.

This is an open access article licensed under the terms of the Creative Commons Attribution Non-Commercial License (http://creativecommons.org/licenses/by-nc/3.0/) which permits unrestricted, non-commercial use, distribution and reproduction in any medium, provided the work is properly cited. 